\title{
Molecular Simulations of Sputtering Preparation and Transformation of Surface Properties of Au/Cu Alloy Coatings Under Different Incident Energies
}

\author{
Linxing Zhang ${ }^{1}$, Sen Tian ${ }^{2,3, *(\mathbb{D}) \text { and Tiefeng Peng }}{ }^{4, *}$ \\ 1 College of Aerospace Engineering, Chongqing University, Chongqing 400044, China; \\ 201731131023@cqu.edu.cn \\ 2 State Key Laboratory of Coal Mine Disaster Dynamics and Control, Chongqing University, \\ Chongqing 400044, China \\ 3 School of Civil Engineering, The University of Queensland, Brisbane, QLD 4072, Australia \\ 4 Key Laboratory of Ministry of Education for Solid Waste Treatment and Resource Recycle, \\ Southwest University of Science and Technology, Mianyang 621010, China \\ * Correspondence: sentian@cqu.edu.cn (S.T.); pengtiefeng@cqu.edu.cn (T.P.); Tel.: +86-23-6510-5093 (S.T.); \\ $+86-816-6089453$ (T.P.)
}

Received: 13 January 2019; Accepted: 19 February 2019; Published: 21 February 2019

\begin{abstract}
The surface properties of coatings during deposition are strongly influenced by temperature, particle fluxes, and compositions. In addition, the precursor incident energy also affects the surface properties of coatings during sputtering. The atomistic processes associated with the microstructure of coatings and the surface morphological evolution during sputtering are difficult to observe. Thus, in the present study, molecular dynamics simulation was employed to investigate the surface properties of $\mathrm{Au} / \mathrm{Cu}$ alloy coatings ( $\mathrm{Cu}$ substrate sputtering by $\mathrm{Au}$ atoms) with different incident energies $(0.15 \mathrm{eV}, 0.3 \mathrm{eV}, 0.6 \mathrm{eV})$. Subsequently, the sputtering depth of the Au atoms, the particle distribution of the $\mathrm{Au} / \mathrm{Cu}$ alloy coating system, the radial distribution function of particles in the coatings, the mean square displacement of the $\mathrm{Cu}$ atoms in the substrate, and the roughness of the coatings were analyzed. Results showed that the crystal structure and the sputtering depth of $\mathrm{Au}$ atoms were hardly influenced by the incident energy, and the incident energy had little impact on the motion of deep-lying atoms in the substrate. However, higher incident energy resulted in higher surface temperature of coatings, and more $\mathrm{Au}$ atoms existed in the coherent interface. Moreover, it strengthened the motion of $\mathrm{Cu}$ atoms and reduced the surface roughness. Therefore, the crystal structure of coatings and the motions of deep-lying atoms in the substrate are not influenced by the incident energy. However, the increase in incident energy will enhance the combination of coatings and the base while optimizing the surface structure.
\end{abstract}

Keywords: alloy coatings; incident energy; surface properties; molecular dynamics; radial distribution function; mean square displacement; roughness

\section{Introduction}

The rapid development of processing and manufacturing industries has placed increasing demands on the safety performance of operation tools and components. This requires the use of protective coatings characterized by high hardness [1,2], high strength and toughness [3,4], heat resistance [5], and wear and corrosion resistance [6,7]. The materials used for thermal protection systems and engine hot section components in the aerospace field are also often subjected to high temperature, mechanical shock, corrosion, and other coupling effects [8]. The use of surface coating technology is an effective means of satisfying the above requirements. Temperature is an important 
determinant of properties for coating materials during their preparation and service [9]. Guo et al. [10] conducted a cyclic thermal loading test on a $1.5 \mathrm{~nm}$ yttria-stabilized zirconia (YSZ) thermal barrier coating, which revealed that the substrate temperature seriously affected the failure characteristics of the coating. Through analyses of the thermal stress, coating thickness, and substrate temperature during thermal spray cooling, Song et al. [11] proposed a corresponding thermal stress analysis model and found that the heat transfer behavior between the coating and the substrate affected the thermal stress distribution. In addition, the surface properties of coatings seriously affect their service performance, a topic that has received extensive scholarly attention as well. However, given the tiny interface structure of coatings, studying their surface properties by conventional experiments and theories is challenging.

Molecular simulation [12-15] has gained wide application in the research of material properties in recent years with the fast advancement of computer technology. Molecular dynamics (MD) is an indispensable computational tool for studying the microstructure and surface morphological evolution of coatings and thin films upon varying incident flux compositions [16,17] and energies [18-20]. MD simulations allow the structure and properties of molecular systems to be analyzed via statistical thermodynamics [18-23]. Fu et al. [24] calculated the generalized stacking fault energy curve of vanadium nitride $(\mathrm{VN})$ ceramic film in the possible slip direction based on MD. They found that the nucleation of dislocations and the movement of partial dislocations were the main mechanisms for plastic deformation in the initial stage. Landman et al. [25] carried out an MD simulation of the loading of Ni needles on the Au surface and showed that the Au surface and the substrate exhibited a range of plastic deformations with the loading of Ni needles. An MD-based study on the surface roughness of $\mathrm{Al}$ found a decrease in the surface roughness with increasing substrate temperature [26]. When the temperature gradient during the sputtering preparation of $\mathrm{Cu} / \mathrm{Au}$ alloy coatings was investigated further [27], results showed that the coherent growth structures and defects enhanced the particle mobility in the $\mathrm{Cu} / \mathrm{Au}$ interface layer, which might result in failure of the coatings under thermal stress. The above body of literature indicates that the surface properties of coatings are subject to multiple factors, such as substrate temperature, coating material, and preparation process, of which temperature is a key factor.

Existing common technologies of surface coating include sputtering, surfacing, electroplating, electroless plating, chemical vapor deposition, chemical bonding, shot peening, etc. For the sputtering process, both the incident energy and substrate temperature of target materials are closely associated with the temperature factor [28-30]. Based on MD, Muller [31] studied the effects of different particle incident energies on coatings in a 2D Lennard-Jones (LJ) system and found that the formation of coatings underwent courses of local heating up, local melting, atomic refactoring, and systematic recrystallization. An MD simulation of the sputtering process of $\mathrm{Cu}, \mathrm{Al}$, and Ni particles on the metal surface by Hsieh et al. [32] revealed that the particle type, cluster size, and incident energy produced varying effects on the coating surface. Lei et al. [33] investigated the $\mathrm{Cu}$ deposition process on the Au substrate by MD and found that the incident energy was greatly influential to the morphology of the $\mathrm{Cu}$ epitaxial layer. Lattice mismatch occurred in the interface layer due to the different lattice constants of $\mathrm{Cu}$ and $\mathrm{Au}$, and partial amorphous particles were present in the interface layer during the sputtering process; this eventually cooled to form a face-centered cubic (FCC) lattice structure. The above body of literature suggests the significant influence of incident energy on the surface properties of coatings. Hence, the effects of different incident energies on the surface properties of coatings are further studied herein using the MD method.

\section{Simulation Method}

MD simulations solve the motion trajectories of all particles in a certain thermodynamic system according to Newton's second law by taking the atoms or molecules in the system as the research unit. The accuracy of MD calculations relies heavily on the interaction potential function between atoms. As the potential function of high-temperature ceramic materials still requires further optimization [24], 
this work uses the potential function of classical embedded atomic method (EAM) to study the effects of $\mathrm{Cu}$ substrate sputtering by $\mathrm{Au}$ atoms with different incident energies on the surface properties of coatings.

\subsection{Model and Computational Method}

Developed by Daw et al. [34], the EAM potential is a potential function model used to calculate the interaction between metal atoms [35-37]. It is based on the density functional theory, which considers that the electron density near a given atom is the sum of the electron densities of that atom and other atoms around it. The specific form of the EAM potential is as follows:

$$
\Phi=\frac{1}{2} \sum_{i \neq j} \varphi\left(r_{i j}\right)+\sum_{i} F\left(\rho_{i}\right)
$$

The first term is an interatomic pair potential [38], where $F$ denotes an embedding function. $\rho_{i}$, which is the electron density at the position of atom $i$, is calculated by summation over the electron densities $\rho\left(r_{i j}\right)$ that derive from neighboring atoms $j$ at a distance $r_{i j}$ from the atom $i$.

$$
\rho_{i}=\sum_{j} \rho\left(r_{i j}\right)
$$

$F$ and $\rho$ are functions of several parameters, which can be determined by fitting known experimental and density functional theory data, such as elastic constant, equilibrium lattice constant, bulk modulus, and vacancy formation energies. The proper description of surface properties also requires fitting surface energies, adatom, and admolecule adsorption energies and migration energies for different reaction pathways [21,22]. Although parameterized with respect to both bulk and surface properties [39], the prediction of reaction pathways and reaction rates obtained via molecular dynamics based on empirical models [40] need verification via ab initio MD [41]. Nevertheless, the EAM potential parameters adopted in this study can simulate the thermal and mechanical properties of $\mathrm{Au} / \mathrm{Cu}$ binary system rather accurately and are therefore considered reliable [42].

\subsection{Materials and Preparation Process}

The computational model of the $\mathrm{Au} / \mathrm{Cu}$ alloy coating sputtering preparation is demonstrated in Figure 1. The size ( $\AA$ ) of $\mathrm{Cu}$ substrate was X: 72, Y: 72, Z: 36 and consisted of three parts of 16,000 atoms. Its bottom was the lower boundary of the simulation box defined by the fixed $\mathrm{Cu}$ atoms. Other substrate atoms were first thermostated at $300 \mathrm{~K}$ for $1 \mathrm{~ns}$ in the NVT ensemble (constant number $(N)$, volume $(V)$, and temperature $(T)$ ). Then, the intermediate $\mathrm{Cu}$ particles were thermostated at around $300 \mathrm{~K}$ in the $N V T$ ensemble as a cooling heat source for the sputtering process. Meanwhile, the top $\mathrm{Cu}$ particles were relaxed in the NVE ensemble (constant number $(N)$, volume $(V)$, and energy (E)) for $1 \mathrm{~ns}$. During the sputtering preparation of coatings, this part of $\mathrm{Cu}$ particles acted directly with the sputtering $\mathrm{Au}$ atoms. The Au atoms were generated randomly from the top of the simulation box (250 ̊ apart from the substrate surface) and sputtered onto the bottom Cu substrate from top down at a rate of $7.5 \times 10^{24}$ atom $/\left(\mathrm{s} \cdot \mathrm{cm}^{2}\right)$ [43] under the NVE ensemble. A total of $4000 \mathrm{Au}$ atoms were sputtered. Various incident energies $(0.15 \mathrm{eV}, 0.3 \mathrm{eV}$, and $0.6 \mathrm{eV})$ were set along the Z-axis to obtain three different coating materials by sputtering. Finally, the prepared system was annealed under NVT ensemble and cooled to $300 \mathrm{~K}$ to statistically analyze the surface properties of the coatings. 


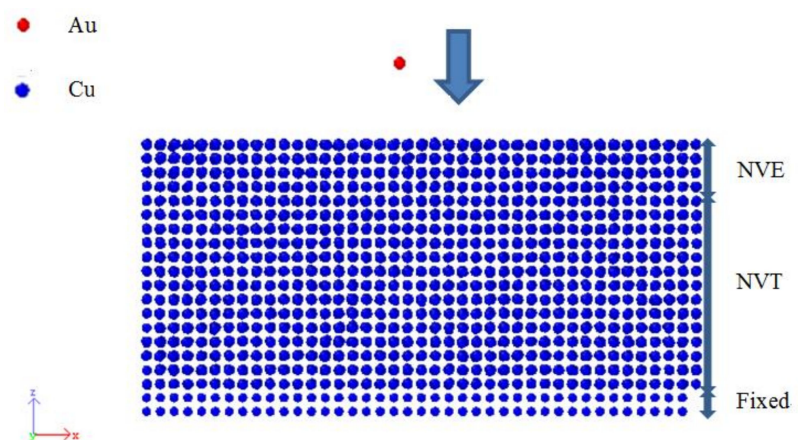

Figure 1. The system model of sputtering preparation for the $\mathrm{Au} / \mathrm{Cu}$ alloy coatings.

The open-source LAMMPS software (Sandia National Laboratories, Albuquerque, NM, USA) was used in this study for the MD simulation [44,45]. The time step in the simulation was set to $1 \mathrm{fs,}$ the $X$ and $Y$-axis directions of the simulation box were periodic boundary conditions, while the Z-axis direction was the mirror boundary condition. The Langevin algorithm was employed to control the temperature of the system, whereas the velocity Verlet algorithm was used to solve the equations of motion for particles $[44,46]$.

\section{Results and Discussion}

\subsection{Particle Distribution}

$\mathrm{Au}$ atoms were sputtered onto the surface of the substrate, which developed a coherent interface with the $\mathrm{Cu}$ atoms at the substrate and formed an FCC lattice structure in the vertical direction (Z-axis direction) after cooling $[27,42,47]$. The structural analysis and post-processing were performed with OVITO [27,42]. Figure 2 illustrates the atomic distribution of the coating system along the Z-axis direction, where the Z-axis origin is the bottommost end of the substrate.
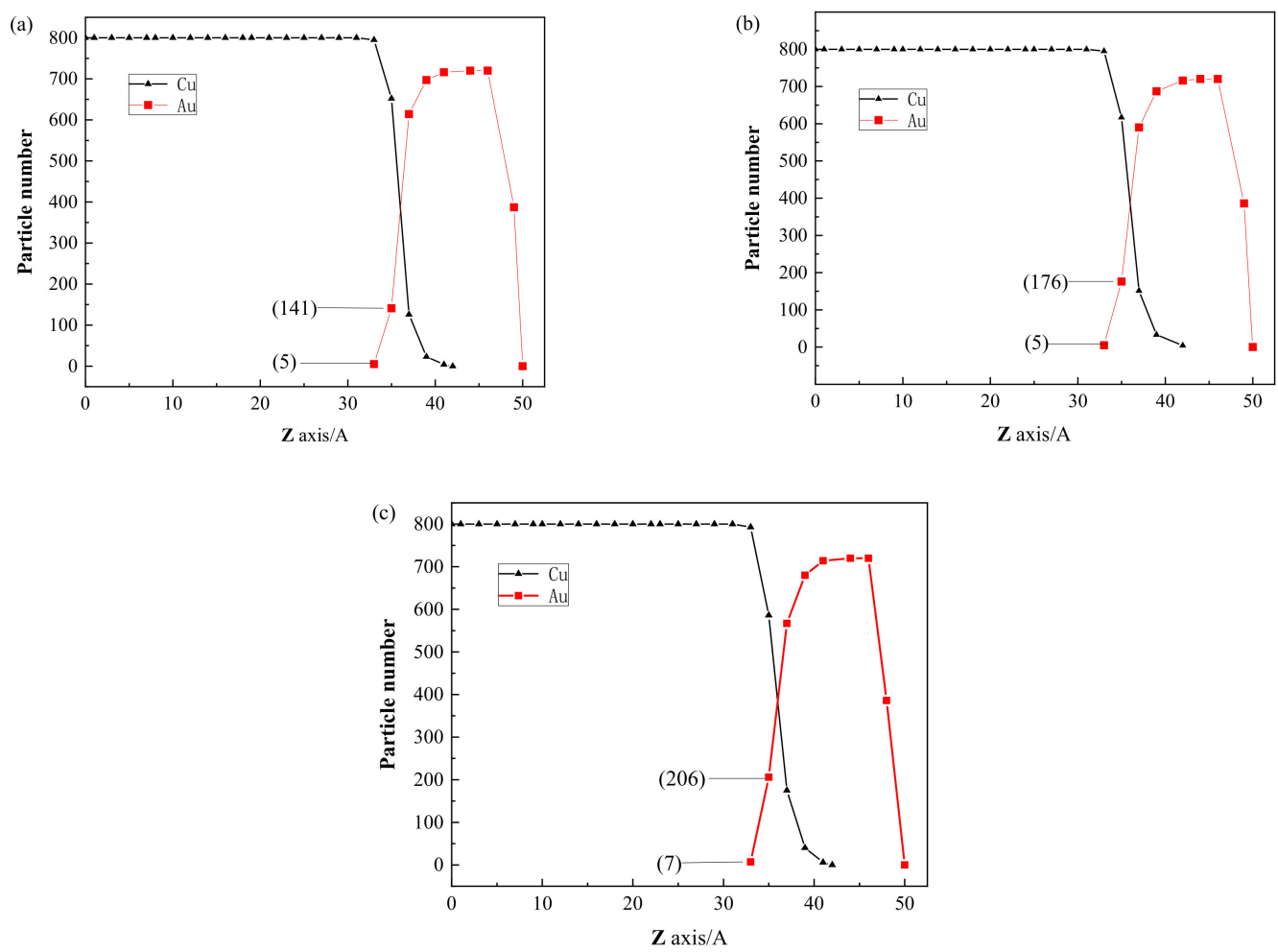

Figure 2. Particle distribution in Z-axis. (a) Incident energy of $0.15 \mathrm{eV}$; (b) incident energy of $0.3 \mathrm{eV}$; (c) incident energy of $0.6 \mathrm{eV}$. 
As can be seen, the sputtering depth of Au atoms was about $33 \AA$ all along at various incident energies, mainly because the maximum energy of incident $\mathrm{Au}$ atoms was insufficient to break down and replace the lower depth $\mathrm{Cu}$ atoms. The fundamental cause of this phenomenon was an increase in the kinetic energy of incident atoms with the increasing incident energy. Nevertheless, the atomic numbers of $\mathrm{Au}$ atoms with incident energies of $0.15 \mathrm{eV}, 0.3 \mathrm{eV}$, and $0.6 \mathrm{eV}$ were 5, 5, and 7, respectively, in the first layer of the coherent interface. The atomic numbers were 141,176, and 206, respectively, in the second layer. After the highly energized $\mathrm{Au}$ atoms hit the substrate, the temperature of the $\mathrm{Cu}$ substrate in the NVE ensemble rose more drastically, which caused the melting of the substrate and eventually led to entry of more Au atoms to the deep layer of the substrate to facilitate the bonding of the coatings with the substrate.

Radial distribution function (RDF) describes the ratio of the probability of presence of another particle to the random distribution at a certain distance around a given particle, which is often used to detect the distribution of particles in a system and their corresponding state [48]. Its statistical formula is as follows:

$$
G(r)=\frac{\mathrm{d} N}{\rho 4 \pi r^{2} \mathrm{~d} r}
$$

where $G(r)$ denotes the RDF of the corresponding particle at a radius $r$ or, in other words, the ratio of the regional density to the average density $\rho$ of system. $N$ denotes the number of particles. Figure 3 displays the RDF of the entire coating systems after annealing. At different incident energies, the trends and numerical values of the particle RDF curves were almost consistent. The first peaks were all located at $2.5 \AA$, after which a series of peaks appeared, indicating that the particles in the different systems were distributed orderly in both near and remote ranges and that the compositions of crystal structures were similar. The $\mathrm{Au} / \mathrm{Cu}$ systems obtained by sputtering at three different incident energies basically showed no difference in the crystal structure composition at the coherent interface.
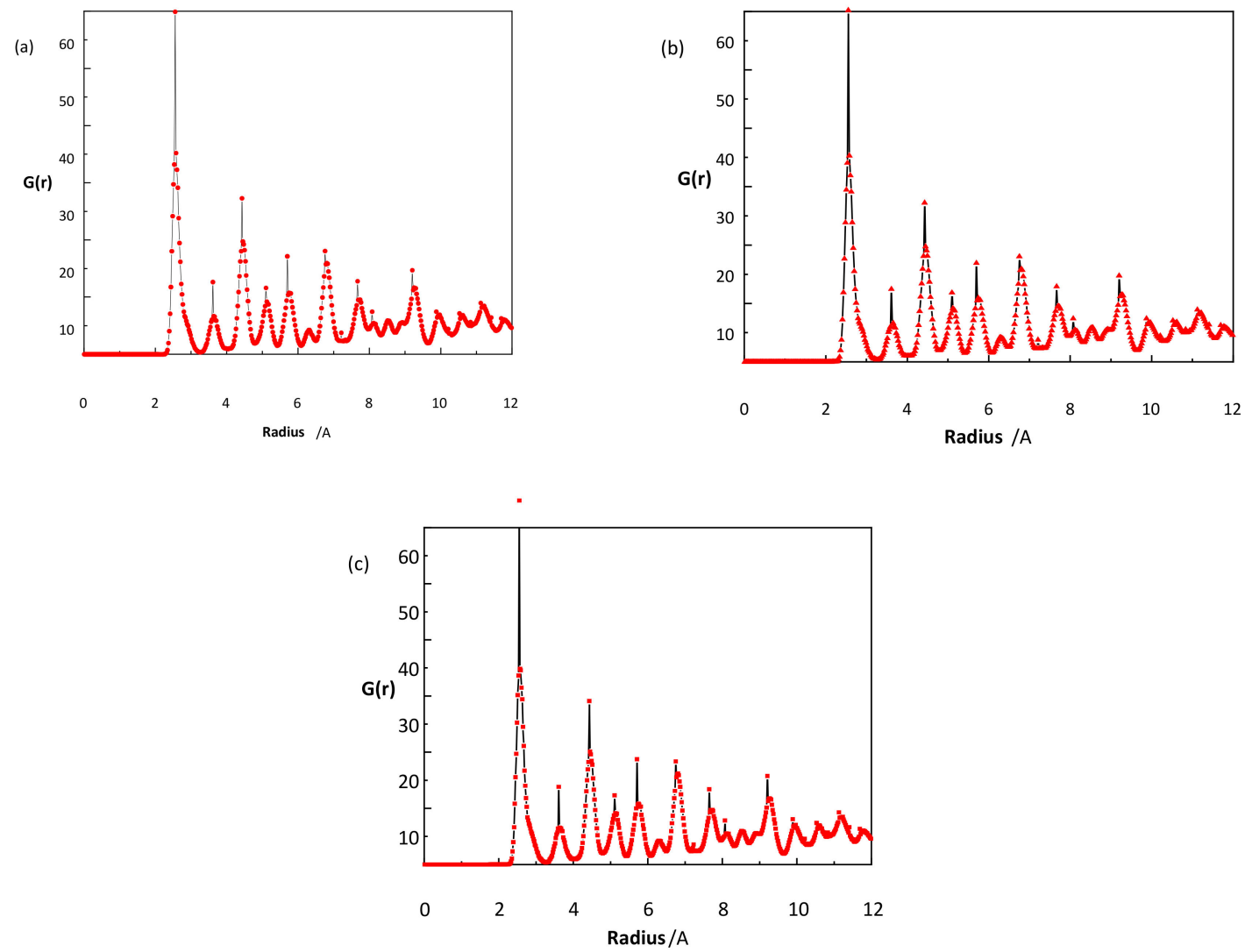

Figure 3. Radial distribution function of particles in coatings. (a) Incident energy of $0.15 \mathrm{eV}$; (b) incident energy of $0.3 \mathrm{eV}$; (c) incident energy of $0.6 \mathrm{eV}$. 


\subsection{Mean Square Displacement of Substrate Atoms}

In MD simulation, the position of particles moves continuously with time, and each particle has varied position at each instant. Mean square displacement (MSD), which is the average of the square of particle displacement, is often used to analyze the mobility of particles [27]. Given the $\mathrm{Cu}$ atoms at the substrate were collided by $\mathrm{Au}$ atoms mainly in the sputtering phase to undergo large displacements, we analyzed the motion properties of substrate $\mathrm{Cu}$ atoms in two ensembles (NVT and NVE) during the sputtering process by MSD, as shown in Figure 4. In the NVT ensemble, the MSD of the Cu atoms was maintained at about $0.05 \AA^{2}$. This not only indicated that the $\mathrm{Cu}$ atoms of the NVT ensemble vibrated fixed in the vicinity of crystal lattice under the EAM potential function but also suggested that the incident energy of $\mathrm{Au}$ atoms was limited, which was unable to effectively influence the movement of this part of $\mathrm{Cu}$ atoms. In the NVE ensemble, on the other hand, the MSD of $\mathrm{Cu}$ atoms increased almost linearly in the sputtering phase with the increasing incident energy, which eventually leveled off. As larger incident energy means larger kinetic energy of Au atoms, after sputtering and impacting the substrate particles of the NVE ensemble, the kinetic energy acquired by $\mathrm{Cu}$ atoms increased, which led to enhanced mobility of $\mathrm{Cu}$ atoms in the system. As the number of sputtered Au particles reached 4000, the Au/Cu system relaxed and cooled by the action of the NVT ensemble, and the whole system underwent a recrystallization process. Upon completion of the recrystallization, the Cu particles at the surface layer of the coating (NVE ensemble) vibrated at the lattice position, and their MSDs were stabilized at certain values.
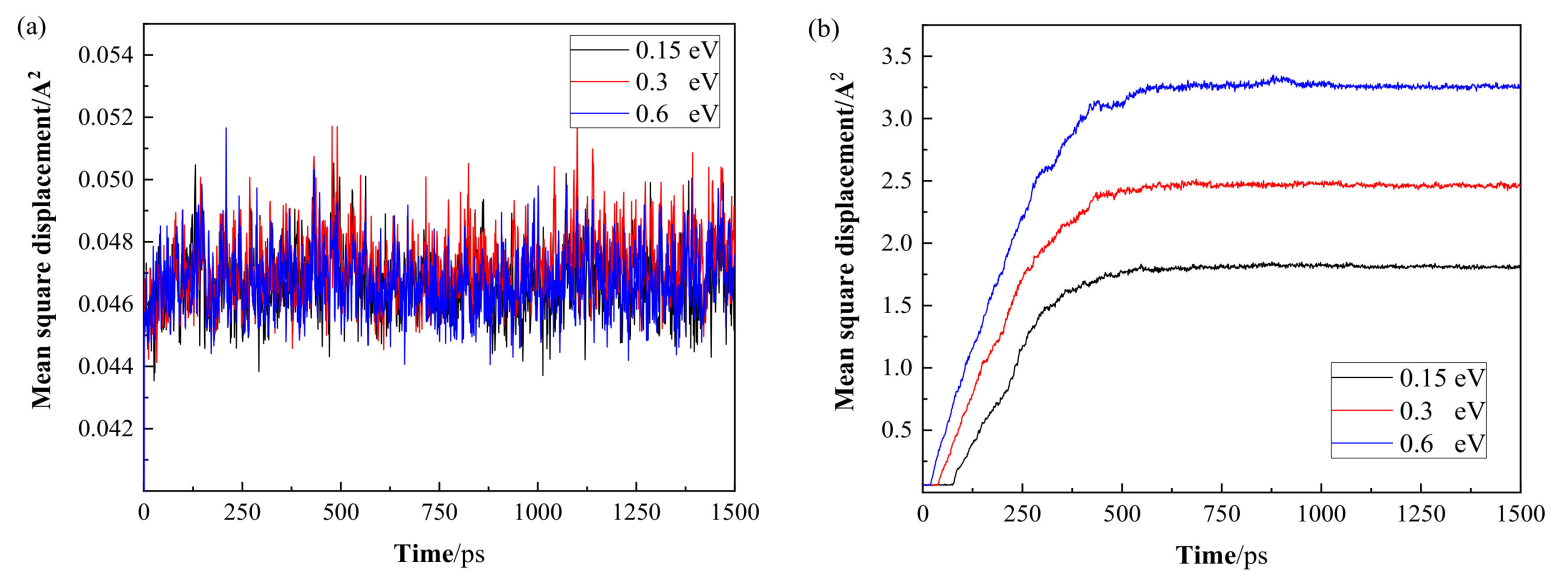

Figure 4. Mean square displacement (MSD) of substrate $\mathrm{Cu}$ atoms. (a) $\mathrm{Cu}$ atoms in NVE ensemble;

(b) $\mathrm{Cu}$ atoms in the $\mathrm{NVT}$ (constant number $(N)$, volume $(V)$, and temperature $(T)$ ) ensemble.

\subsection{Surface Roughness of Coatings}

Surface roughness, as a major indicator of coatings, is inevitably varied by the incident energy. In this study, the roughness $R$ was calculated in terms of the root mean square of the height position of coating surface particles [49-51]. Its statistical formula is as follows [52]:

$$
R=\sqrt{\frac{\sum_{i=1}^{n}\left(Z_{i}-\bar{Z}\right)^{2}}{n}}
$$

where $n$ denotes the total number of particles on the coating surface, $Z_{i}$ denotes the vertical coordinate of surface particles, and $\bar{Z}$ denotes the mean vertical coordinate thereof. The surface roughness of the $\mathrm{Au} / \mathrm{Cu}$ alloy coatings with the incident energy of $0.15 \mathrm{eV}, 0.3 \mathrm{eV}$, and $0.6 \mathrm{eV}$ before and after annealing was obtained through calculations, as shown in Table 1. As can be seen, there were certain changes in the surface roughness of coatings before and after annealing. Both before and after annealing, the surface roughness decreased with the increasing incident energy. At the same incident energies, 
the roughness values after annealing were all less than that before annealing. This was because the larger incident energy raised the temperature at the coating surface to make its state tending to a molten liquid phase, and the surface roughness was reduced correspondingly under surface tension. Meanwhile, during the annealing process, the structure of the coating systems was optimized to reduce the specific area and lower the free energy, and their surface roughness was also reduced further.

Table 1. Surface roughness of $\mathrm{Au} / \mathrm{Cu}$ alloy coatings before and after annealing.

\begin{tabular}{cccc}
\hline \multirow{2}{*}{ Status of Coatings } & \multicolumn{3}{c}{ Incident Energy } \\
\cline { 2 - 4 } & $\mathbf{0 . 1 5} \mathbf{~ e V}$ & $\mathbf{0 . 3} \mathbf{~ e V}$ & $\mathbf{0 . 6} \mathbf{~ e V}$ \\
\hline Before annealing $(\AA)$ & 2.19 & 2.05 & 2.03 \\
After annealing $(\AA)$ & 2.05 & 1.93 & 1.87 \\
\hline
\end{tabular}

\section{Conclusions}

In this study, the surface properties of $\mathrm{Au} / \mathrm{Cu}$ alloy coatings prepared by sputtering at different incident energies were studied by analyzing the particle distribution, particle radial distribution function, particle motion mean square displacement, and roughness of the coatings by the MD simulation method. Under the simulated conditions of this study, the incident energy produced no effect on the sputtering depth of Au atoms. Nevertheless, greater incident energy caused more drastic rise in the substrate temperature, so more $\mathrm{Au}$ atoms were mixed with the substrate $\mathrm{Cu}$ atoms to form a coherent interface, which facilitated the bonding of the coatings with the substrate. Incident energy had no substantial effect on the crystal structure of particles in various regions of the coatings, nor could it affect the motion of deep-lying atoms in the substrate. In spite of this, greater incident energy still signified stronger mobility of the $\mathrm{Cu}$ atoms in the surface layer of the substrate. The incident energy significantly influenced the surface roughness of coatings, as indicated by lower coating roughness with its increase. In addition, annealed coatings exhibited better roughness than those before annealing optimization.

Author Contributions: L.Z. participated in the design of the work, methodology, data interpretation, and analysis for the work; carried out the statistical analyses; and drafted the manuscript. S.T. designed the study; participated in data interpretation, analysis for the work, and methodology; carried out the statistical analyses; and drafted the manuscript. T.P. participated in design of the work, data interpretation, and analysis for the work and helped carry out the statistical analyses.

Funding: This study was financially supported by the Chongqing Research Program of Basic Research and Frontier Technology (cstc2018jcyjAX0522), the National Natural Science Foundation of China $(11332013,51502311)$, the Program for Changjiang Scholars and Innovative Research Team in University (IRT_17R112), and the Innovation Support Program for Chongqing Overseas Returnees (cx2018071).

Acknowledgments: The authors would like to acknowledge the colleagues from the State Key Laboratory of Coal Mine Disaster Dynamics and Control for their perspectives and suggestions related to data collection and statistical analysis.

Conflicts of Interest: The authors declare no conflict of interest.

\section{References}

1. Reeswinkel, T.; Sangiovanni, D.G.; Chirita, V.; Hultman, L.; Schneider, J.M. Structure and mechanical properties of TiAlN-WN ${ }_{x}$ thin films. Surf. Coat. Technol. 2011, 205, 4821-4827. [CrossRef]

2. Mikula, M.; Plašienka, D.; Sangiovanni, D.G.; Sahul, M.; Roch, T.; Truchlý, M.; Gregor, M.; Čaplovič, L.; Plecenik, A.; Kúš, P. Toughness enhancement in highly NbN-alloyed Ti-Al-N hard coatings. Acta Mater. 2016, 121, 59-67. [CrossRef]

3. Kindlund, H.; Sangiovanni, D.G.; Lu, J.; Jensen, J.; Chirita, V. Effect of WN content on toughness enhancement in $\mathrm{V} 1-x \mathrm{~W} x \mathrm{~N} / \mathrm{MgO}(001)$ thin films. J. Vac Sci. Technol. A 2014, 32, 030603. [CrossRef] 
4. Mikula, M.; Truchly, M.; Sangiovanni, D.G.; Plašienka, D.; Roch, T.; Gregor, M.; Ďurina, P.; Janík, M.; Kúš, P. Experimental and computational studies on toughness enhancement in Ti-Al-Ta-N quaternaries. J. Vac Sci. Technol. A Vac. Surf. Films 2017, 35, 060602. [CrossRef]

5. Mayrhofer, P.H.; Mitterer, C.; Hultman, L.; Clemens, H. Microstructural design of hard coatings. Prog. Mater. Sci. 2006, 51, 1032-1114. [CrossRef]

6. Voevodin, A.A.; Zabinski, J.S. ; Supertough wear-resistant coatings with 'chameleon' surface adaptation. Thin Solid Films 2000, 370, 223-231. [CrossRef]

7. Yang, Q.; Zhao, L.R.; Patnaik, P.C.; Zeng, X.T. Wear resistant TiMoN coatings deposited by magnetron sputtering. Wear 2006, 261, 119-125. [CrossRef]

8. Freund, L.B.; Suresh, S. Thin Film Materials: Stress, Defect Formation and Surface Evolution. Cambridge University Press: Cambridge, UK, 2003.

9. Tian, Z.T. , Hu, H., Sun, Y. A molecular dynamics study of effective thermal conductivity in nanocomposites. Int. J. Heat Mass Transf. 2013, 61, 577-582. [CrossRef]

10. Guo, H.B.; Vassen, R.; Stover, D. Atmospheric plasma sprayed thick thermal barrier coatings with high segmentation crack density. Surf. Coat. Technol. 2004, 186, 353-363. [CrossRef]

11. Song, Y.; Zhuan, X.; Wang, T.J.; Chen, X. Evolution of thermal stress in a coating/substrate system during the cooling process of fabrication. Mech. Mater. 2014, 74, 26-40. [CrossRef]

12. Hu, J.; Liu, C.; Li, Q.; Shi, X. Molecular simulation of thermal energy storage of mixed $\mathrm{CO}_{2} / \mathrm{IRMOF}-1$ nanoparticle nanofluid. Int. J. Heat Mass Transf. 2018, 125, 1345-1348. [CrossRef]

13. Li, Q.; Xiao, Y.; Shi, X.; Song, S. Rapid evaporation of water on graphene/graphene-oxide: A molecular dynamics study. Nanomaterials 2017, 7, 265. [CrossRef] [PubMed]

14. Temirel, M.; Hu, H.; Shabgard, H.; Boettcher, P.; McCarthy, M.; Sun, Y. Solidification of additive-enhanced phase change materials in spherical enclosures with convective cooling. Appl. Therm. Eng. 2017, 111, 134-142. [CrossRef]

15. Jerome, M. , Herbert M.U. Ferrite-to-austenite and austenite-to-martensite phase transformations in the vicinity of a cementite particle: A molecular dynamics approach. Metals 2018, 8, 602.

16. Edstrom, D.; Sangiovanni, D.G.; Hultman, L.; Petrov, I.; Greene, J.E.; Chirita, V. Large-scale molecular dynamics simulations of TiN/TiN(001) epitaxial film growth. J. Vac Sci. Technol. A 2016, 34, 041509. [CrossRef]

17. Xu, Z.; Zeng, Q.; Yuan, L.; Qin, Y.; Chen, M.; Shana, D. Molecular dynamics study of the interactions of incident $\mathrm{N}$ or Ti atoms with the TiN(001) surface. Appl. Surf. Sci. 2016, 360, 946-952. [CrossRef]

18. Edström, D.; Sangiovanni, D.G.; Hultman, L.; Petrov, I.; Greene, J.E.; Chirita, V. Effects of incident N atom kinetic energy on TiN/TiN(001) film growth dynamics: A molecular dynamics investigation. J. Appl. Phys. 2017, 121, 025302. [CrossRef]

19. Adamovic, D.; Munger, E.P.; Chirita, V.; Hultman, L.; Greene, J.E. Low-energy ion irradiation during film growth: Kinetic pathways leading to enhanced adatom migration rates. Appl. Phys. Lett. 2005, 86, 211915. [CrossRef]

20. Adamovic, D.; Chirita, V.; Munger, E.P.; Hultman, L.; Greeneb, J.E. Enhanced intra-and interlayer mass transport on $\mathrm{Pt}(111)$ via 5-50 eV Pt atom impacts on two-dimensional Pt clusters. Thin Solid Films 2006, 515, 2235-2243. [CrossRef]

21. Sangiovanni, D.G.; Tasnadi, F.; Hultman, L.; Petrov, I.; Greene, J.E.; Chirita, V. N and Ti adatom dynamics on stoichiometric polar TiN(111) surfaces. Surf. Sci. 2016, 649, 72-79. [CrossRef]

22. Sangiovanni, D.G.; Edström, D.; Hultman, L.; Petrov, I.; Greene, J.E.; Chirita, V. Ti adatom diffusion on $\mathrm{TiN}(001)$ : Ab initio and classical molecular dynamics simulations. Surf. Sci. 2014, 627, 34-41. [CrossRef]

23. Servet, K.; Fatih, A.C.; Koray, K. The impact of Pt concentration on crystal growth mechanism in Pt-Pd binary alloy system in the context of molecular dynamics. Metals 2018, 8, 926.

24. Fu, T.; Peng, X.H.; Zhao, Y.B.; Li, T.; Li, Q.; Wang, Z. Molecular dynamics simulation of deformation twin in rocksalt vanadium nitride. J. Alloys Compd. 2016, 675, 128-133. [CrossRef]

25. Landman, U.; Luedtke, W.D.; Burnham, N.A.; Colton, R.J. Atomistic mechanisms and dynamics of adhesion, nanoindentation, and fracture. Science 1990, 248, 454-461. [CrossRef] [PubMed]

26. Cheng, Y.; Lee, C. Simulation of molecular dynamics associated with surface roughness on an Al thin film. Surf. Coat. Technol. 2008, 203, 918-921. [CrossRef] 
27. Li, Q.; Peng, X.; Peng, T.; Tang, Q.; Zhang, X.; Huang, C. Molecular dynamics simulation of Cu/Au thin films under temperature gradient. Appl. Surf. Sci. 2015, 357, 1823-1829. [CrossRef]

28. Chen, Y.; Xiao, H.; Liu, Y.; Chen, X. Effects of temperature and strain rate on mechanical behaviors of Stone-Wales defective monolayer black phosphorene. J. Phys. Chem. C 2018, 122, 6368-6378. [CrossRef]

29. Song, Y.; Lv, Z.; Liu, Y.; Zhuan, X.; Wang, T.J. Effects of coating spray speed and convective heat transfer on transient thermal stress in thermal barrier coating system during the cooling process of fabrication. Appl. Surf. Sci. 2015, 324, 627-633. [CrossRef]

30. Yildiz, A.; Celik, F. Atomic concentration effect on thermal properties during solidification of Pt-Rh alloy: A molecular dynamics simulation. J. Cryst. Growth 2017, 463, 194-200. [CrossRef]

31. Muller, K.H. Cluster-beam deposition of thin films: A molecular dynamics simulation. J. Appl. Phys. 1986, 61, 2516-2521. [CrossRef]

32. Hsieh, M.; Averback, R.S. Molecular dynamics simulations of collisions between energetic clusters of atoms and metal substrates. Phys. Rev. B 1992, 45, 4417-4430. [CrossRef]

33. Lei, H.; Hou, Q.; Hou, M. Low energy slowing down of nanosize copper clusters on gold(111) surface. Nucl. Instrum. Methods Phys. Res. Sect. B 2000, 164, 537-545. [CrossRef]

34. Daw, M.S.; Foiles, S.M.; Baskes, M.I. The embedded-atom method: a review of theory and applications. Mater. Sci. Rep. 1993, 9, 251-310. [CrossRef]

35. Cheng, Y.; Cui, W.; Wang, L.; Peng, C.; Wang, S.; Wang, Y. Vitrification and crystallization of phase-separated metallic liquid. Metals 2017, 7, 73. [CrossRef]

36. Kazanc, S. Molecular dynamics study of pressure effect on crystallization behaviour of amorphous $\mathrm{Cu}-\mathrm{Ni}$ alloy during isothermal annealing. Phys. Lett. A 2007, 365, 473-477. [CrossRef]

37. Luyten, J.; De Keyzer, J.; Wollants, P.; Creemers, C. Construction of modified embedded atom method potentials for the study of the bulk phase behaviour in binary Pt-Ph, Pt-Pd, Pd-Ph and ternary Pt-Pd-Rh alloys. Calphad 2009, 33, 370-376. [CrossRef]

38. Karachevtsev, V.A.; Stepanian, S.G.; Karachevtsev, M.V.; Adamowicz, L. Graphene induced molecular flattening of meso-5,10,15,20-tetraphenyl porphyrin: DFT calculations and molecular dynamics simulations. Comput. Theor. Chem. 2018, 1133, 1-6. [CrossRef]

39. Sangiovanni, D.G.; Edström, D.; Hultman, L.; Chirita, V.; Petrov, I.; Greene, J.E. Dynamics of Ti, N, and TiNx $(x=1-3)$ admolecule transport on TiN(001) surfaces. Phys. Rev. B 2012, 86, 155443. [CrossRef]

40. Edstrom, D.; Sangiovanni, D.G.; Hultman, L.; Chirita, V.; Petrov, I.; Greene, J.E. Ti and N adatom descent pathways to the terrace from atop two-dimensional TiN/TiN(001) islands. Thin Solid Films 2014, 558, 37-46. [CrossRef]

41. Sangiovanni, D.G.; Mei, A.B.; Edström, D.; Hultman, L.; Chirita, V.; Petrov, I.; Greene, J.E. Effects of surface vibrations on interlayer mass transport: $\mathrm{Ab}$ initio molecular dynamics investigation of Ti adatom descent pathways and rates from TiN/TiN(001) islands. Phys. Rev. B 2018, 97, 035406. [CrossRef]

42. Li, Q.; Wang, M.; Liang, Y.; Lin, L.; Fu, T.; Wei, P.; Peng, T. Molecular dynamics simulations of aggregation of copper nanoparticles with different heating rates. Physica E 2017, 90, 137-142. [CrossRef]

43. Chung, C.Y.; Chung, Y.C. Molecular dynamics simulation of nano-scale Fe-Al thin film growth. Mater. Lett. 2006, 60, 1063-1067. [CrossRef]

44. Plimpton, S. Fast parallel algorithms for short-range molecular dynamics. J. Comput. Phys. 1995, 117, 1-19. [CrossRef]

45. Freitas, R.; Asta, M.; de Koning, M. Nonequilibrium free-energy calculation of solids using LAMMPS. Comput. Mater. Sci. 2016, 112, 333-341. [CrossRef]

46. Chang, Q.; Xie, J.; Mao, A.; Wang, W. Study on interface structure of $\mathrm{Cu} / \mathrm{Al}$ clad plates by roll casting. Metals 2018, 8, 770. [CrossRef]

47. Hossein, E.; Parvin, S.; Florian, M.P. Local bond order parameters for accurate determination of crystal structures in two and three dimensions. Phys. Chem. Chem. Phys. 2018, 20, 27059-27068.

48. Li, Q.; Liu, C.; Chen, X. Molecular characteristics of dissociated water with memory effect from methane hydrates. Int. J. Mod. Phys. B 2014, 28, 1450062. [CrossRef]

49. Weng, F.; Yu, H.; Chen, C.; Wan, K. High-temperature oxidation behavior of Ni-based superalloys with $\mathrm{Nb}$ and $\mathrm{Y}$ and the interface characteristics of oxidation scales. Surf. Interface Anal. 2014, 47, 362-370. [CrossRef] 
50. Wang, L.; Jiang, W.G.; Li, X.W.; Dong, J.; Zheng, W.; Feng, H.; Lou, L. Effect of surface roughness on the oxidation behavior of a directionally Solidified Ni-based superalloy at $1100{ }^{\circ}$ C. Acta Metall. Sin. 2015, 28, 381-385. [CrossRef]

51. Çelik, Y.H.; Kilickap, E.; Güney, M. Investigation of cutting parameters affecting on tool wear and surface roughness in dry turning of Ti-6Al-4V using CVD and PVD coated tools. J. Braz. Soc. Mech. Sci. Eng. 2016, 39, 2085-2093. [CrossRef]

52. Davey, W.P. Precision measurements of the lattice constants of twelve common metals. Phys. Rev. 1925, 25, 753-761. [CrossRef]

(C) 2019 by the authors. Licensee MDPI, Basel, Switzerland. This article is an open access article distributed under the terms and conditions of the Creative Commons Attribution (CC BY) license (http:// creativecommons.org/licenses/by/4.0/). 